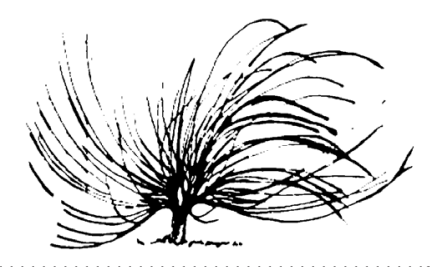

\title{
La interculturalidad en la formación de profesores de enseñanza de la filosofía: Un encuentro con la comunidad de Kcha'bli
}

\author{
Juan Rafael Gómez Torres ${ }^{1}$ \\ Universidad Nacional \\ Costa Rica \\ ggomezz1@yahoo.es
}

\begin{abstract}
Nosotros no somos mitos ni del pasado, ni del presente, sino que somos pueblos activos. Mientras que haya un indio vivo en cualquier rincón de América y del mundo, hay un brillo de esperanza y un pensamiento original
\end{abstract}

(Rigoberta Menchú).

Este y el siguiente escrito, fueron discutidos en el encuentro "Enseñanza de la filosofía: indisciplinando la didáctica", realizado del 6 al 10 de noviembre de 2017 en la División de Educología del Centro de Investigación y Docencia en Educación (CIDE), de la Universidad Nacional de Costa Rica (UNA en adelante). Este evento contó con la participación de panelistas argentinos de gran calibre académico, el Dr. Alejandro Cerletti y la Dra. Gabriela D'Odorico, ambos especialistas y formadores de profesores de la enseñanza de la filosofía. Como se ha comentado, este encuentro tuvo la particularidad de ser organizado por estudiantes de la carrera de la Enseñanza de la filosofía de la UNA, específicamente los estudiantes del Módulo Pedagógico III: Investigación e innovación educativa en la práctica docente de la enseñanza de la filosofía (2017).

Este ensayo intentará dar cuenta de una experiencia intercultural educativa de más de 10 años en la comunidad indígena Bribri de Kachabri, ubicada en el Territorio de Talamanca, Limón. Tal actividad

1 Académico de la División de Educología, CIDE, UNA 
ha sido realizada en gran parte mediante el Proyecto de Investigación denominado Alfabetización Crítica, el cual está adscrito a la División de Educología de la UNA. Destacaremos el aporte de esta actividad académica de extensión, investigación, docencia y producción a la formación de profesores/as de Enseñanza de filosofía en la universidad antes citada.

\section{Algunas bases teóricas que despertaron el encuentro}

En la etapa previa a las visitas hacia la comunidad indígena señalada, nos dimos a la tarea de profundizar teóricamente sobre la filosofía y pedagogía latinoamericana, especialmente sobre la pedagogía crítica y la intercultural. A finales de los noventa y principios del dos mil, aún existía, teóricamente hablando, una cierta tendencia en Costa Rica a caracterizar la situación de los pueblos indígenas desde una antropología económica (en el mejor de los casos) y desarrollista, en el peor; es decir, abiertamente moderna o modernizante. El debate resultaba así más plural o sustantivo en países donde la población indígena era y es muy amplia, caso de México, Guatemala, Perú y Bolivia. Asimismo, se explica esta última situación por los conflictos sociales producto de los regímenes de Seguridad Nacional o sencillamente totalitarios, cuya lógica o proceder respondía y responde incluso hoy, solapadamente, al principio ontocida de "tierra arrasada".

Fuera del marco académico dominante del país, autores como Helio Gallardo, Francisco Gutiérrez, Franz Hinkelammert, Ingemar Hedström, Fernando Mires, Raúl Fornet-Betancourt, Héctor Díaz Polanco, Bonfil Batalla, Enrique Dussel, Carlos Lekensdorf y otros, planteaban la necesidad de abandonar las teorías eurocéntricas y etnocidas. La propuesta, más allá del rol economicista, llegaba a la estructuración de la educación formal indígena mediante programas de Educación Bilingüe Intercultural (EBI), que no solían ir más allá de lo técnico ni de lo cognitivo, dejando de lado la desigualdad social provocada o, al menos, agravada por el Estado. A pesar de su limitación, la EBI puso en discusión la interculturalidad como metodología para establecer criterios necesarios para la concreción de encuentros e intervenciones convenidas y justas en dichas comunidades, sin que estuvieran regidas por la vieja matriz colonial racista, sexista y clasista, sino por reglas ético normativas convenidas desde y con las partes. 
En los años anteriores, el debate estaba todavía dominado por la disyuntiva Primer Mundo/Segundo o Tercer Mundo, por lo que la dimensión cultural aparecía a veces subsidiaria de las relaciones económicas de explotación (proveniente del marxismo mecánico -salvo la posición latinoamericanista de José Mariategui, Enrique Dussel, Pablo Freire, Aníbal Quijano y otros autores que leen a Marx desde lo local-), llevándoles a establecer una ética materialista nuestroamericana, pese también a las falencias y falsas generalidades que puedan comprender estas categorías. De tal modo, el encuentro cultural, entendido en su amplia dimensión como ser y estar para la vida con el mundo, incluyendo lo económico tardó un poco más, hasta afianzarse en lo que hoy se denomina interculturalidad (Fornet-Betancourt) o, específicamente, transmodernidad (Enrique Dussel).

Hay que dejar claro que, ciertamente, la dimensión de lo económico fue, desde la conquista y la colonia, la dimensión central de la imposición europea en el mundo iberoamericano (es decir, sometido por el imperialismo); pero no es la única ni la más importante de las relaciones de un encuentro, pues el mismo Marx define al ser humano no solo como económico, sino como ser que se produce a sí mismo materialmente, al relacionarse, ahora sí, productivamente, para la vida, con la naturaleza y con los demás seres humanos. Y son, precisamente, estas dos relaciones (ser humano/ser humano, ser humano/naturaleza) las que distinguen este proceso de autoproducción, ambas siendo focos del ya citado onticidio, producto del economicismo expresado primeramente en mercantilismo, luego en liberalismo económico, desarrollismo y actualmente mediante el neoliberalismo, neoconservador y fundamentalista, de tipo no solo monetarista, sino también religioso.

\section{II. ¿Cosmología o cosmogonía indígena?}

Otra discusión en el debate intercultural, más allá de los temas económicos o de la desigualdad social, es el de la diferencia entre cosmología (epistémicamente legitimada por el saber científico positivista) y el de cosmogonía (epistémicamente "antropologizadas", es decir, descartadas desde esta misma ciencia positiva). En uno u otro sentido, toda cosmología es una cosmogonía, mas no ciertamente a la inversa. $Y$ es hasta muy recientemente que se vienen planteando (últimos cincuenta años) las relaciones entre cosmogonías no occidentales 
o pre-occidentales y sus respectivos corpus teórico/cosmogónicos, incluyendo datos de observación y teorización racional/empírica, con aquellos propios de la "cosmología" positiva postnewtoniana (ligada sobre todo a la mecánica cuántica y a la relatividad general propuesta por Einstein) que tienen importantes "similitudes" con las cosmogonías indígenas.

Esta observación, desde un punto de vista educativo, es de gran importancia, ya que estos saberes, por ejemplo, la idea de que todo es y no es (proceso dialéctico), idea antigua planteada por Heráclito, o por el budismo zen, implican semejanzas sorprendentes. Tampoco significa esto que hay equivalencia, sino más bien una relación netamente intercultural en su trasfondo cosmogónico. En este sentido, viene al caso distinguir similitudes interculturales, más que aparentes relaciones de correspondencia teórica entre las distintas culturas, sin caer en el simplismo de achacar a otros pueblos, asincrónica o anaespacialmente, la invención completa de la cosmología occidental o cosmogonías aparentemente similares. En esas visiones cosmogónicas de este pueblo, la vida sigue fluyendo, la espiritualidad es liberadora o las enseñanzas de sus deidades (deidad en el caso de los Bribri), más que un recuerdo, son formas de prácticas de vida que dan sentido a su existir.

\section{Pedagogía intercultural como camino para desnaturalizar esencialismos culturales}

Por Pedagogía, entendemos una socio-praxis que reflexiona sobre la práctica educativa con el fin de transformar al ser humano y a la sociedad. Por ende, no es neutral ni técnica. Lo técnico es un elemento más entre otros como lo estético, lo político, lo ético, lo curricular, lo evaluativo, lo epistemológico, lo didáctico o lo investigativo. Lo central es el diálogo situacional de aprendizaje abierto, flexible y crítico. Lo anterior implica que, como dijimos, la Pedagogía no es neutra, sino ante todo un deber ser, una intencionalidad o un lugar de reflexión de lo educativo para adquirir críticamente valores éticos, estéticos y políticos, así como para desarrollar capacidades, habilidades y destrezas necesarias para (con)vivir en una sociedad más justa, equitativa y solidaria.

La Costa Rica de hoy vive, al menos en las esferas formales, una pedagogía tradicional, tecnicista, repetidora, centrada en el hacer humano que necesita el mundo empresarial o los grandes capitales, dejando 
de lado su trascendental tarea de transformación. Por ende, según señala la defensora de los habitantes de Costa Rica, una educación conservadora, racista, clasista, con fobias a la diversidad sexual, cultural y social (Monserrat Sagot, La Nación, 6/3/18, p. 10a).

Si a la Pedagogía le damos un apellido como el de intercultural, eso nos lleva a explicar lo que entendemos por tal adjetivo. Lo concebimos como un proyecto ético político del buen convivir entre culturas distintas a través de la diversidad, la que a su vez parte de la diferencia. Digo buen convivir pues convivimos muy mal según las cifras de abandono de adultos mayores, de femicidios, de niños en la calle, de agresiones y violaciones a niños/as y mujeres en general, asesinatos, humillaciones a las poblaciones sexualmente diversas, abandono y desprecio para con las poblaciones indígenas y las personas con alguna discapacidad, de racismo, miseria, destrucción de la naturaleza, fenómenos que en nuestro país son escandalosos (Gómez y Mora, 2011), por lo que la buena convivencia se construye mediante parámetros éticos y políticos y la educación puede ser fundamental para ello. Así visto, la Pedagogía Intercultural es ante todo una pedagogía crítica en situación, una lucha permanente por la inclusión, el buen convivir, la justicia social y contra la desigualdad social.

Dicho de otro modo, la Pedagogía Intercultural es una pedagogía comprometida con la diversidad/alteridad. Es un acto reflexivo donde pongo a mi yo ante el espejo con el fin de comprender que no somos nada sin el/la Otro/a, ¿quién o qué soy si no hay otro/a para diferenciarme? De allí la máxima de Hinkelammert, "yo soy solo si tú eres" (2017, p. 31). Soy si somos, soy en interdependencia con los otros/as y con la naturaleza. De este modo, la diferencia es un principio ético material.

En la Pedagogía, ser distintos o diferentes es visto como constitutivo del ser humano, lo que provoca una especie de desigualdad natural que no tiene por qué inducir a la desigualdad moral. La primera solo nos indica cómo somos o lo que somos, mientras la segunda cómo debemos ser. Por eso, para evitar la discriminación cultural se vuelve necesario acudir a la igualdad moral, ella es un cimiento de la diversidad, y por ende de la Pedagogía Intercultural. Se parte de ese principio entendiéndolo como la condición diferenciada para adquirir derechos a partir de la compensación y la equidad.

Por ejemplo, los indígenas de nuestro país, por su cultura, son muy distintos a los mestizos del Valle Central, pero esa diferencia solo 
produce desigualdad si se mide a todos por igual (igualitarismo). Si no se les compensa (discriminación positiva) según su situación propia, si no se les dan las condiciones materiales necesarias para superar las "desventajas", éticamente no se debe tratar igual al desigual pues de hacerlo se genera abiertamente discriminación social. Aquí la justicia pasa por dar a cada uno según su necesidad.

Como afirmamos, la Pedagogía Intercultural lucha contra la discriminación social, pues la discriminación es un acto político ejercido sobre quienes son considerados inferiores por ser distintos, restringiéndoles oportunidades y llevando a la desigualdad social, en muchos casos expresada en miseria o hasta la indigencia. La discriminación como acción política destructiva parte de la idea sobre las esencias humanas (naturaleza humana), ello a pesar de que no exista un elemento aglutinador de la especie humana (Araya y Villena, 2008). Las esencias son construidas para dar identidad, su abuso suele ser discriminatorio, quien no se ajuste a ellas suele ser rechazado por anormal (por ser diferente). De allí que la identidad es una invención humana, modificable, relativamente inestable y fuente de diferenciación. Es un eje simbólico o de imaginación (Jiménez, 2012). Separa o unifica según los imaginarios que le den cohesión a la misma: biológicos, religiosos, políticos, sociales, idiomáticos, otros.

Por tanto, la discriminación social no suele ser un efecto de la naturaleza sino un proyecto político con tintes fascistas, pues lo anormal suele ir asociado con la desposesión de la propiedad privada o de los medios de producción. El anormal pertenece al mundo de lo inferior, de lo feo, de lo atrasado, de lo bárbaro, de lo salvaje o de lo pobre. Como mencionamos anteriormente, se idealizan atributos cohesionados cayendo en un "narcicismo de las diferencias irrelevantes" que no reconoce las semejanzas, como señala Alexander Jiménez (2012, p. 318). Ese no reconocimiento del semejante nos lleva a reafirmarnos desde la mismidad y dejar por fuera a la alteridad, lo que puede simbolizar un suicidio colectivo, pues prevalece en las relaciones un miedo a ser negados o absorbidos (Araya y Villena, 2008). Dichas manifestaciones de rechazo del otro/a se han incrementado, o más bien se dejan ver claramente en el sistema educativo mediante el acoso, la violencia y el autoritarismo escolar, en las redes sociales digitales donde se ha democratizado la mediocridad, la fanfarria y el odio y en la acción de la sociedad mediante la persecución a la diversidad, como hemos señalado. 
Remarcando lo hasta aquí dicho, la pedagogía Intercultural, como proyecto ético político de igualdad social, lucha abiertamente contra los esencialismos culturales y contra toda pretensión hegemónica de imponer matrices socioculturales de índole discriminatorio (racistas/ sexistas/clasistas). De allí que todo docente tenga la responsabilidad de luchar contra la discriminación e injusticia social; ser docente no solo es pararse frente a un grupo y enseñar técnicamente algo, es ante todo enseñar ese saber hacer acompañado de elementos críticos tales como por qué, para qué, para quién, además de transmitir valores éticos, estéticos y políticos en el proceso educativo, pues no solo importa el hacer técnico, sino también el convivir bien, el desarrollar la sensibilidad estética, el vivir con dignidad y hasta el saber morir. Temas que podemos resignificar o redimensionar mediante el encuentro y aprendizaje con otros pueblos, como el bribri, que es el caso específico de este escrito y desde donde hemos cuestionado la idea de la filosofía occidental negada a los otros/as, lo que nos lleva a preguntarnos: ¿la filosofía es una propiedad privada? Al respecto, tratamos ese tema en el acápite denominado "la enseñanza de la filosofía desde nuestra realidad latinoamericana: el caso de la Universidad Nacional de Costa Rica".

\section{El encuentro propiamente dicho y su importancia en la for- mación del profesorado}

En el 2003, comenzamos a acercarnos a las comunidades profundas u originarias, más conocidas como pueblos indígenas, en las montañas tropicales de Talamanca. Específicamente, hemos colaborado con la comunidad de Kcha'bli (Kachabri); una vez allí, iniciamos conversaciones (al principio un poco difíciles, dadas las necesarias mediaciones lingüísticas y culturales) con distintos indígenas y, en especial, con Jairo Sánchez. Poco a poco se fue estableciendo un proceso de comunicación entre las partes, nos cedimos números telefónicos, contactos, y otros aspectos necesarios para el encuentro, partiendo metodológicamente de la Investigación Acción Participativa (IAP) con el fin de realizar un encuentro justo y duradero.

Desde la UNA logramos buscar apoyo para concertar una primera y, luego, sucesivas citas con el Awà (médico tradicional) Ricardo Morales, gran sabio de la cultura Bribri. En este momento nuestro interés académico no estaba cobijado bajo el paraguas del Proyecto de 
Investigación citado, lo que significa que el encuentro no contaba con ninguna mediación institucional. Asimismo, hay que reconocer que este proceso implicó un lento autoaprendizaje en conjunto con algunos académicos y estudiantes cercanos, con los cuales debatí ideas sobre lo hasta ese entonces logrado.

Jairo Sánchez, quien es traductor y cantor del Sabak, nos contactó con el Awà Ricardo Morales de la Asociación Awàpa a quien fuimos a conocer. En esa visita él nos trató con mucha seriedad y amabilidad, conversamos sobre temas ligados al mundo bribri y a su relación con el Sikua (no indígena); durante ese primer encuentro, comenzamos a entender la gran distancia que existe entre la cultura occidentalizada o sincrética costarricense y la propia de esos pueblos profundos y olvidados, cuando no colonizados y destruidos por esta, en todas las formas posibles de la violencia cultural y estructural ejercida por el Estado Nacional, en aspectos económicos, culturales, sociales, religiosos, educativos, de la salud, entre otros. Estos pueblos, con justa razón, manifiestan una gran desconfianza y escepticismo hacia los Sikua, aunque a pesar de ello están dispuestos a dialogar en condiciones justas y en un mismo plano metalingüístico.

En el 2004 y 2005, regresamos a la comunidad de Kachabri invitados por Jairo a una serie de actividades culturales y me reencontré varias veces con el Awà Ricardo. Hablamos en estas ocasiones sobre varios temas, ahondando sobre la relación entre bribris y sikuas, dejando claro que somos distintos por antonomasia y cosmovisión ya que, según esta misma cosmovisión, los Bribri hasta en la muerte se encuentran con los sikuas; pero tales contactos o encuentros no se revuelven, pues todos los seres humanos tienen un lugar y tiempo distintos según la misma cosmovisión indígena, ya que fueron hechos por/y como seres distintos (en lugares y tiempos también diferentes), y es a ese lugar donde se debe retornar. Insistió el Awà varias veces que el encuentro es inevitable, pero manteniendo las diferencias originarias y regido, como hemos señalado, por una ética de la alteridad o intercultural en condiciones de justicia, igualdad y equidad.

La teoría intercultural ayuda a la preparación y facilitación del encuentro justo y equitativo entre culturas. Es a su vez un proceso educativo que puede enriquecer el trabajo pedagógico (especialmente desde la universidad, como se verá más adelante). Dicha teoría insiste tanto en las similitudes como en las diferencias, desde un "principio 
epistemológico débil", en contra tanto del determinismo como del relativismo cultural extremista (Mora, 2015). Para ello, se debe partir, necesariamente, de los sujetos más débiles o en condiciones de desigualdad/disparidad, siempre y cuando esto no implique un daño para ninguno de los participantes ni para terceros (principio central de la Teología y Filosofía de la Liberación: la opción por los pobres y los condenados -Fanon, 1983- de la Tierra y la Tierra misma). O bien, como señala el fundador de la Teología de la liberación, Gustavo Gutiérrez, se "trata de una espiritualidad que ose echar raíces en el suelo de la opresión y haga germinar las semillas de la liberación" (Gutiérrez, 2013, p. 56).

En el 2006 nos involucramos de lleno en la formación de profesores de Enseñanza de la Filosofía en la División de Educología/CIDE/ UNA; ese mismo año retornamos a Talamanca. En esa ocasión, el Awà Ricardo nos narró algunas historias bribri, todo ello traducido igualmente por el cantor Jairo Sánchez, de las cuales más que similitudes con occidente encontré relaciones cosmogónicas muy valiosas para nuestro existir en equilibrio y armonía con la naturaleza.

Le preguntamos al Awà sobre la relación entre ellos y las universidades del país y me dijo que no existía casi ninguna, a excepción de unas visitas donde una profesora llamada Maritza, de la Universidad de Costa Rica (UCR), trajo a sus estudiantes a finales de los noventa, pero desde que ella se pensionó desapareció toda relación con las universidades. Narró que en el pasado hubo otros intercambios, sobre todo con antropólogos y lingüistas, pero fueron negativos, pues solían llevarse información y publicar sus libros sin el permiso de los mayores, lo que les había enojado mucho. A partir de esa información, el Awà me propuso llevar grupos de estudiantes de la Universidad.

De inmediato pensamos que esas relaciones profundas que podían resignificar nuestras relaciones con el mundo podrían ser experimentadas por otras personas, especialmente por estudiantes universitarios y fundamentalmente por estudiantes de Enseñanza de la Filosofía, a quienes tradicionalmente se les ha negado la posibilidad de las filosofías y el filosofar en y desde otras culturas no occidentales u occidentalizadas. Con ello podríamos iniciar un vínculo filosófico con culturas originarias desde donde podríamos revisar la concepción clásica y positivista de la filosofía y del filosofar. 
Para el Awà Ricardo iniciar con los grupos a mi cargo "estaba bien", pues me comentó que ellos necesitaban, deseaban y debían tener aliados ante cualquier lucha de defensa de los derechos indígenas. También arguyó que los Sikuas conocen poco sobre ellos y que mucho de lo que se dice en el Valle Central (o zona metropolitana) sobre los indígenas se encuentra distorsionado por los imaginarios sociales y políticos (Jiménez, 2012), lleno de prejuicios, estereotipos y estigmatizaciones (Araya y Villena, 2008), situación de la que no escapa en general el sistema educativo costarricense ya que, según la Mesa Nacional Indígena, es "hasta 1985 que por razones diversas que se reconoce por primera vez en la historia, en una norma de rango ejecutivo -de manera específica (...)- el derecho de los pueblos indígenas a recibir una educación adecuada a su realidad tradicional..." (MNICR, 2007, p. 86).

Es, sin embargo, a partir de 1999, con la reforma al artículo 76 de la Constitución Política, que se da visibilidad a las lenguas de indígenas, siendo esto crucial dado que con ellas se sostienen las formas propias de pensamiento y, por ende, sus culturas. Tal artículo establece que: "El español es el idioma oficial de la Nación. No obstante, el Estado, velará por el mantenimiento y cultivo de las lenguas indígenas nacionales".

En general, es a partir de la adhesión de Costa Rica al Convenio 169 de la OIT en 1992 que el sistema jurídico costarricense incorpora a la educación indígena estatal, pues dicho convenio elabora un capítulo dedicado a la educación de los pueblos indígenas, "reivindicando en el plano de la igualdad de oportunidades, el derecho de los pueblos indígenas a acceder a una educación en las mismas condiciones con los demás ciudadanos (Artículo 26)" (MNICR, 2007, p. 87). A pesar de las pretensiones de tal convenio, Costa Rica está aún muy lejos de su cumplimiento, pues de forma continua, como señalan la Mesa Nacional Indígena y muchas otras organizaciones de defensa y promoción de los derechos indígenas, se da un constante desconocimiento de la realidad, intereses y necesidades de estos pueblos y se violentan continuamente sus derechos (MNICR, 2007, p. 87).

Por lo anterior, como señala el Awà Ricardo, para no seguir reproduciendo ese tipo de injusticias o de olvidos interesados, es necesario conocer profundamente a los pueblos y romper prejuicios desacertados, cuestión que resultó inédita tanto para profesores como para estudiantes de la Enseñanza de la filosofía, quienes pudieron tener una experiencia 
sobre la forma de vida y cosmovisión bribri (altamente compleja como han descrito otros autores) y de su propia forma de hacer y vivir la filosofía.

El Awà Ricardo considera bueno establecer una relación de intercambio justo de saberes con la universidad, donde ellos enseñen o compartan su saber con el estudiantado. Sugiere que los visitantes apoyen con víveres y otras necesidades básicas de forma voluntaria (sin caer en el simple asistencialismo), así como con un apoyo económico que cubra, en este caso, la estancia y la alimentación en el lugar. Nos mostramos de acuerdo con esa iniciativa, pese a que personalmente me carcomía la incertidumbre, el nerviosismo y la inseguridad sobre cada uno de los pasos que iban surgiendo en el transitar. En cierta medida debía ser antropológicamente interculturalizado, es decir, ceder antes que empujar una relación pedagógica estéril por ficticia y epistemológicamente infundada como se ha señalado en el presente escrito.

La propuesta del Awà Ricardo implicaba así, indirectamente por supuesto, el sentido de alcanzar una transformación intercultural de la pedagogía universitaria en general y de la enseñanza de la filosofía en particular, a partir de los desafíos reconocidos en el diálogo con los pueblos originarios de Costa Rica. Pero ese reto genera perplejidad, sabiendo que una buena forma de relacionarse con estas comunidades es haciendo y no prometiendo. Ese precepto implicó informarnos sobre cómo realizar una gira educativa en la Universidad, cuál era la burocracia por vencer, especialmente cuando los tiempos de la Universidad y de los pueblos indígenas tienden a ser profundamente discordantes, por lo que encontrar un paralelismo casi implicaba ya la misma concreción de una propuesta intercultural, es decir, encontrar un punto en el tiempo/espacio en común. Según la cosmogonía bribri, tiempo y espacio existen indisolublemente unidos, se encuentran en un punto específico del $k \underline{a}$. Con el pasar de las giras aprendimos a sortear esos obstáculos propios de la distancia entre la Universidad como "torre de marfil" y las comunidades como espacios abiertos.

Seguidamente, coordinamos con las y los estudiantes de Enseñanza de la filosofía, para quienes esta era una aventura de aprendizaje. Enseguida coordiné con la Asociación Awàpa, en ese entonces bajo la coordinación del Awà Ricardo. La primera gira se llevó a cabo el segundo viernes de octubre del 2006. La comunidad nos recibió con los brazos abiertos, nos prepararon comidas tradicionales, así como organizaron una serie de actividades culturales que dan cuenta de su ancestralidad, 
costumbres aún vivas y no de un remoto pasado, según afirman autores como Sebreli (1992) y sin logos como señala Salazar-Bondy (1988), quienes desprecian estos saberes otros por considerarlos fuera de la razón occidental.

Entre las actividades que nos mostraron estaban: la molienda de maíz, el aporreo de fríjoles, la pela del banano, la tejida de la suita, la corta de la chonta, el tiro al blanco con arco y flecha, la cerbatana; también nos contaron historias en el Alowe (lugar que representa a las montañas) y en el Úsule (lugar que representa la creación del Universo), las que se contaban en bribri con traducción simultánea al español, entre otras.

Se puede observar que muchas de esas costumbres fueron asumidas por las comunidades campesinas de nuestro país, mismas que los Planes de Ajuste Estructural (PAE) dictados por el Fondo Monetario Internacional (FMI) y el banco Mundial (BM), así como los Tratados de Libre Comercio (TLC) han condenado a la extinción, dado sus ataques furibundos al campesino y al indígena, despojándoles de la tierra y de las formas de producción colectiva o solidarias, aumentando la pobreza en la ruralidad, destruyendo la naturaleza y enviando gran cantidad de esta población a los anillos urbanos de miseria. Con las y los estudiantes podíamos analizar estas y otras realidades de nuestro país producto de políticas internacionales y de las élites neocoloniales que nos gobiernan.

En esa primera visita a la mayoría de los visitantes nos impactó la historia narrada sobre el Duwàlök. Cuenta el Awà Ricardo que una vez sus ancestros

(...) salieron a cazar con lanzas y vieron a una danta y se fueron tras ella y de repente se dieron cuenta que llegaron a una casa; había un señor en esa casa y el señor les invitó a pasar y les dijo que esa forma de cazar animales no era buena, no deben herirlo, a mí y a Sibö no nos parece. Por eso Duwàlök les enseñó por cuatro días muchas cosas y le enseñó a la danta herida. Les dio permiso de irse y les dijo que no contaran nada de lo que vieron hasta 4 días después. Duwàlök llevó a los dos cazadores a ver el Nmá que es el pescado, Duwàlök los llevó para que vieran el daño que hacen a los animales y a los cultivos. (Morales, 2006) 
Otro aspecto que nos llamó la atención en la socialización de la experiencia que se hace en el aula universitaria fue lo que el Awà dijo sobre los dos mundos bribri, el de la oscuridad y el de la luz. El primero es sagrado, es del origen y el retorno, el segundo es donde vivimos. Aunque son distintos, son continuación de un ciclo inseparable. Narra el sabio que “(...) en el mundo de Duwàlök todo tiene un significado distinto que aquí en la tierra, allá las cosas se ven distintas, por ejemplo, para nosotros el pescado es un animal mientras que para él es yuca, el zaino es banano, el camarón para él es chile, la piedra es cangrejo..." (Morales, 2006).

Para el acercamiento, como ya se acotó, nos apoyamos en la metodología de la Investigación Acción Participativa (IAP). Ella nos propone que para realizar el encuentro partamos del mutuo reconocimiento y que se trabaje desde y sobre las semejanzas, propiciando una comunicación abierta y profunda.

En ese dialogar, la Asociación Awàpa, conforme pasaban las giras y los encuentros, fueron agregando actividades culturales tales como el baile del Sorbón, el Sabak, la preparación del cacao y de algunas artesanías, el tejido de canastas, la trampa para atrapar animales como pavas y codornices, entre otras, y se fue sumando la presencia de personas de la comunidad con distintos cargos ancestrales, los cuales dependen o son dados gracias al rol clánico que les corresponde según lo estableció Sibö, asignado matrilinealmente, de modo que hoy en día nos visitan Awàpa, Oköpa, Siatemi, Shorutemi, Bikakla, Sabak, entre otros.

Esta experiencia intercultural que inició con un grupo en el 2006 se ha venido intensificando según las posibilidades de la comunidad; ya para el 2009, la División de Educología se había interesado en este proyecto pedagógico intercultural, por lo que algunos de los otros compañeros siguieron la exhortación de hacer giras a la comunidad de Kachabri. Tres situaciones permitían este impulso, (a) la apertura de la comunidad para recibirnos, (b) la claridad epistemológica, ética y política del encuentro y (c) la iniciativa de las y los profesores de Educología de realizar giras educativas dado que eran muy pocas las que se realizaban hasta ese momento. Aunque Educología no solo realiza giras educativas a Kachabri, sí es cierto que aumentó el número de visitas de grupos de nuestra unidad académica a dicha comunidad indígena.

Para el 2011, se incorporaron algunas visitas de la Escuela de Filosofía de la UNA, así como algunos posgrados como el de Estudios 
Latinoamericanos, la División de Educación Básica y de la División de Educología. Para el 2012, se añade la Escuela de Estudios Generales de la UNA y la Sede de Occidente de la Universidad de Costa Rica, la primera con mucha regularidad y la segunda de modo más esporádico. Desde ese año las visitas han sido más frecuentes y continuas. Igualmente, en 2012, se oficializó este proyecto pedagógico intercultural mediante el Proyecto de Alfabetización Crítica adscrito a la División de Educología de la UNA.

Desde la comunidad también ha habido cambios interesantes. En el 2014 y 2015, mediante el Proyecto Alfabetización Crítica, realizamos un mini proyecto de reciclaje en la escuela del lugar. Compartiendo en la comunidad nos dimos cuenta de que el problema de los desechos como el plástico está inundándolos. El Awà Lizandro López, otro de los Awà de la comunidad, nos contó que eso era un gran problema dado que muchos tiran la basura al suelo porque la costumbre ancestral de devolverle todo a Iriria (la niña tierra) estaba muy arraigada, pues el bribri se comprometió con Sibồ a devolverle los desechos, ahora diríamos orgánicos, a la tierra para que se alimente. Él comenta que muchos se dan cuenta de la destrucción que provoca el plástico, pero hay gente que aún lo ignora y otros a quienes no les interesa, por lo que se hizo necesario colaborar en esta tarea de concientización sobre los efectos del plástico en la tierra.

Por ello consideramos importante trabajar con la escuela del lugar, aunque allí ya había iniciativas del Ministerio de Educación Pública (MEP) y de la Municipalidad de Talamanca, por lo que nos ocupamos por dos años en apoyar esas tareas de concientización y manejo de los desechos sólidos. Colaboramos mediante talleres para la correcta utilización de módulos ecológicos. El trabajo casi descansó en el voluntariado de nuestros estudiantes asistentes, los que en realidad hacen factible el trabajo colaborativo y solidario de Alfabetización Crítica.

En el 2012, la comunidad había creado un grupo de recolección de desechos plásticos, vidrio, latas y otros desechos no orgánicos. El grupo se llamaba Kaksöl y estaba conformado por niños y niñas. La historia de su nombre es muy interesante pues corresponde al de un pájaro carpintero que ayudó en conjunto con otro, el Tzné, a crear la música; el primero hizo bien la tarea y el segundó falló. Al primero Sibö lo recompensó con una manta de color roja y al segundo le asignó la función de recoger los desechos de la elaboración del Sabak. De allí que para ellos 
la música y la recolección de los desechos vayan de la mano, así como el cuidado y aprendizaje de las plantas medicinales pues todo se hace bajo la guía de un Awà.

En ocasiones se le ayudó a dicho colectivo con materiales, mediante la colaboración de organizaciones externas, que eran recolectados por los estudiantes universitarios. En la actualidad esta tarea la realiza con mayor ahínco un grupo de mujeres de la comunidad vecina de Amubre denominado "Mujeres que labran la tierra", así como la Escuela de Kachabri y la Municipalidad de Talamanca, quienes han seguido el compromiso de esos niños y niñas, lo que ha mejorado la situación con dichos desechos.

Como puede verse, esas acciones en apariencia sencillas se estaban convirtiendo en un modo de comunicación pedagógica, de aprendizaje y de encuentro entre el pueblo indígena y la práctica extensiva de la Universidad dentro de la comunidad. El estudiantado podía evidenciar mediante acciones como esta, la necesidad de apoyar a la comunidad para que siguiera practicando sus tradiciones, enfrentando las distorsiones que suele producir occidente.

Otro hecho a destacar es que en el 2013 se unió la Asociación Dtzöta, y en el 2014 la Asociación Dual, centros de preservación de la cultura que pasaban por momentos difíciles para mantener sus edificaciones y tareas de propagación de sus saberes debido a la poca ayuda que reciben del Estado en particular y del resto de la sociedad costarricense en general. En la actualidad, los grupos de estudiantes que visitan la localidad se distribuyen entre las tres asociaciones de forma equitativa.

Desde diciembre del 2014, como parte de una Pedagogía Intercultural, se ha venido implementado una evaluación del proyecto con las tres asociaciones presentes, las cuales dan a conocer sus impresiones sobre el trabajo realizado por la Universidad Nacional en el lugar, mediante las giras educativas. Se valora el impacto a la comunidad, las debilidades, los beneficios, y se han determinado protocolos para la estancia en dicha población. Suelen recalcar la importancia del encuentro como un acto de mutuo beneficio, tanto del aprendizaje invaluable que recibimos los visitantes como de la ayuda que les ha dado Alfabetización Crítica para continuar con su labor de divulgación cultural, tanto adentro como afuera de su comunidad.

En general, en esas valoraciones hechas por las asociaciones, se ha dicho que las visitas han generado beneficios a toda la comunidad 
pues se reactiva el comercio interno y justo a través de la compra de productos como aves de corral, huevos de gallina, cerdos, palmito, plátano, banano, cacao, frijoles, pejibaye, entre otros productos de la zona. También se impulsa la mano de obra de personas que se les paga por su colaboración en el mantenimiento del lugar, la hala de productos, la cocinada, entre otras labores. Se ha reafirmado la importancia de donaciones como materiales didácticos a la escuela por parte de los y las estudiantes de la universidad.

A su vez, de un modo más indirecto, manifiestan que también se han beneficiado otras personas de la comunidad como las encargadas del transporte (boteros y autobuseros), pulperos, ferreteros (donde se suelen hacer compras para donativos y colaboraciones hechas por las y los estudiantes).

En este sentido, el papel de la Universidad responde a las necesidades de la realidad social, sin cambiar su sentido. Ello porque, como afirma Roig, la Universidad en América Latina no ha estado exenta de los peligros que la región ha enfrentado a causa del imperialismo, lo que implica que la Universidad debe luchar por su autonomía, originalidad y contextualidad, apoyándose para ello en el saber diverso de los pueblos, pues "los arquetipos deben ser siempre buscados en la propia realidad socio-cultural de América Latina, sin olvidar por cierto que dentro de esa realidad propia está la historia humana con toda su plenitud" (Roig, 1998, pp. 55-56). Se trata de luchar por una universidad libre o liberada, un centro educativo productor de pedagogías alternativas, o como señala Angulo,

En lugar de dejarnos distraer por el artificio de las competencias, podríamos comenzar a pensar las pedagogías del siglo XXI, pensar nuevos modos de afrontar los retos del conocimiento científico, intentar entender cómo son las generaciones que llegarán en un futuro a nuestras aulas, diseñar espacios para la autonomía, la creatividad, comunicación y el intercambio en nuestras universidades, aceptar que la educación y formación universitaria no es neutral y que tenemos que asumir valores éticos, que tenemos una responsabilidad social ineludible, no solo con el entorno inmediato sino con aquellas sociedades que nos necesitan y que, a su vez, desde luego, necesitamos enseñar al alumnado que 
nuestro mundo es por lo que hemos hecho, diverso, complejo y frágil. (2011, p. 203)

Otro beneficio del encuentro apuntado, según el criterio de las asociaciones, es el impulso cultural que ellos/ellas gestionan hacia el resto de la comunidad, pues señalan que muchos niños/as van a escuchar las enseñanzas de los Awàpa cuando están los grupos de la Universidad, lo que también aprovechan otros miembros de la población. También señalan que el resto de la comunidad va apreciando la importancia del valor de su cultura al percatarse que gente ajena a su realidad se interesa de su historia y no vienen a aprovecharse de ellos. Además, manifiestan que las giras incentivan a la continuidad de sus roles clánicos al percatarse de la trascendencia que tienen para el buen funcionamiento de la agrupación y para el intercambio con los visitantes.

En general, las giras educativas han impulsado la necesaria transformación de la educación superior costarricense, al menos para el caso de las carreras de enseñanza de la UNA, y especialmente a la Enseñanza de la filosofía, mediante el diálogo establecido ya hace diez años entre la pedagogía universitaria y la comunidad indígena de Kcha'bli, pues este intercambio de saberes anticoloniales despierta una gran sensibilidad en el estudiantado, quienes a partir del encuentro cuestionan sus prácticas cotidianas a veces racistas, xenofóbicas y clasistas, entre otros tipos de discriminación muchas veces naturalizados de forma inconsciente. Al menos eso suelen compartir en las socializaciones de la experiencia que se hace en el aula universitaria. Los estudiantes de esta carrera logran evidenciar que la filosofía también está en otras partes.

En múltiples ocasiones las y los estudiantes manifiestan que la experiencia con esta comunidad es invaluable, comparten que una de las cosas más difíciles de romper es el esencialismo de la mismidad, comentan que ese quiebre espiritual es urgente para acabar con una filosofía verticalista, etnocida y eurocéntrica que se les impone desde el currículo como verdad única y última.

\section{A modo de cierre}

La División de Educología y las demás Escuelas de la UNA y la UCR que participan de este encuentro intercultural, se benefician pedagógicamente de gran manera, todos aprendemos a mantener el contacto 
reflexivo con la realidad del Otro sin pretender que sean como nosotros. La reflexión constante sobre los encuentros con las comunidades nos ha llevado a revisar nuestras prácticas áulicas, a cambiar en muchos casos la didáctica, el currículo y hasta la evaluación. Desde la pedagogía, se ha buscado incorporar actividades más lúdicas, cercanas a la naturaleza y a la vida cotidiana. Del currículo se ha procurado latinoamericanizar más los contenidos, de modo que sean más pertinentes y contextuales al estudiantado, mientras que la evaluación se ha venido horizontalizando pues, como creen estas comunidades, el saber es colectivo, nadie en particular es su dueño, se aprende viviendo, practicando y transformando la realidad. Parafraseando a Freire (2005), nadie educa a nadie, todos aprendemos juntos mediados por la realidad. De tal modo, evaluar debería ser un proceso participativo, donde los estudiantes puedan ayudar a crear los criterios de su evaluación, puedan evaluar la labor docente y puedan disfrutar la misma como parte de un proceso lúdico y fundamental para ser una mejor persona humana.

\section{Referencias}

Angulo, J. (2011). "La voluntad de distracción". En Gimeno, J. (compilador). Educar por competencias, ¿qué hay de nuevo?, tercera edición. Madrid: MORATA.

Araya, M. y Villena, S. (2008). Hacia una pedagogía del encuentro cultural: discriminación y racismo. Cuadernos para la Ciudadanía. San José: Editorial UCR.

Fanon, F. (1983). Los condenados de la tierra. Segunda edición. México: FCE.

Freire, P. (2005). Pedagogía del oprimido. Quincuagésima sexta edición. México: Siglo XXI.

Gómez, J. y Mora, M. (2011). Pedagogía del futuro: educación, sociedad y alternativas. En Revista Ensayo Pedagógicos Número Especial, julio-diciembre. Costa Rica: División de Educología de la UNA.

Gutiérrez, G. (2013). La espiritualidad de la liberación: escritos esenciales. España: Sal Terrae.

Hinkelammert, F. (2017). La vida o el capital: El grito del sujeto vivo y corporal frente a la ley del mercado. Antología especial. Argentina: CLACSO/ALAS. 
Jiménez, A. (2012). Imaginarios, migraciones y formas de estar juntos. Convivencia, migración, e interculturalidad en Costa Rica. En Raúl Fornet Bentancourt (Hrsg.) La convivencia humana: problemas y posibilidades en el mundo actual. Una aproximación intercultural. Alemania: MVerlang Mainz.

Mesa Nacional Indígena de Costa Rica (MNICR). (2007). Programa de observancia y verificación de derechos de los pueblos 2007 indígenas de Abya Yala: Informe alternativo presentado por los pueblos indigenas al informe presentado por el estado de costa rica al comité contra la discriminación racial de la convención internacional sobre la eliminación de todas las formas de discriminación racial, 71 periodo de sesión 30 de julio al 18 agosto. Recuperado de http://www2.ohchr.org/english/bodies/cerd/docs/ ngos/mni2_costarica.pdf

Mora, M. (2015). Algunos problemas de fundamentación y justificación sociológica: Apuntes en el marco del debate teórico de la sociología contemporánea. En Revista ABRA, vol. 35(50), 1-19. Recuperado de http://dx.doi.org/10.15359/abra.35-50.1

Morales, R. (2006). Historia del Duwàlök. Recopilada por Juan Gómez Torres académico de la Universidad Nacional y traducida por Jairo Sánchez. Heredia: Educología/UNA.

Salazar-Bondy, A. (1988). ¿Existe una filosofia de nuestra América? Undécima edición. México: Siglo XXI.

Sebreli, J. (1992). El asedio a la modernidad. Argentina: Editorial Sudamericana. 